РАЗОВ Павел Викторович - доктор социологических наук, доцент; профессор департамента социологии, истории и философии Финансового университета при Правительстве РФ (125993, Россия, 2. Москва, Ленинградский пр-кт, 49; pvrazov@fa.ru)

ЮШКОВА Светлана Александровна - кандидат экономических наук, Dr. Habilitatus, доцент; доцент департамента социологии, истории и философии Финансового университета при Правительстве РФ (125993, Россия, г. Москва, Ленинградский пр-кт, 49; ysa67@таil.ru)

ДОРОШЕНКО Марина Витальевна - специалист по маркетинговым коммуникациям брендингового агентства «Style Yои» (121170, Россия, г. Москва, Кутузовский пр-кт, 36, стр. 23, офис 112; mar.dorosh95@gmail.com)

\title{
ИНДИВИДУАЛЬНЫЙ ПЕНСИОННЫЙ КАПИТАЛ: СТРАТЕГИИ ДЕЙСТВИЯ
}

Аннотация. В статье рассматриваются аспекты введения индивидуального пенсионного капитала (ИПК) взамен существующей накопительной пенсионной системы РФ. Авторы соотносят позитивные и негативные стороны этого этапа пенсионной реформы, делают прогнозы и формулируют рекомендации, а также делают предположения о специфике реакций на систему ИПК гражданами с различными пенсионными стратегиями.

Ключевые слова: индивидуальный пенсионный капитал, пенсионная реформа, пенсионная система, пенсионные стратегии

$\mathrm{P}$ еформирование системы пенсионного обеспечения в России продолжается. Первый этап, который заключался в т.ч. в повышении пенсионного возраста, введен в силу. Второй этап реформы предусматривает внедрение системы индивидуального пенсионного капитала (ИПК), которая предлагает гражданам самостоятельно формировать накопительную часть своей пенсии. По замыслу авторов реформы, предполагается, что внедрение системы ИПК сможет решить как минимум две проблемы в России: во-первых, повысит благосостояние будущих пенсионеров, во-вторых, окажет положительное влияние на экономику страны. Граждане получают инструмент для формирования образа жизни после выхода на заслуженный отдых. Экономика страны получает пенсионные накопления как источник долгосрочных инвестиций.

Следует отметить, что внедрение ИПК не является чем-то новым для пенсионной системы России, ведь элементы накопительной системы были внедрены в результате пенсионной реформы 2002 г. и практически перестали действовать в 2014 г. Отметим, что до 2014 г. за тех граждан, чей тариф - это страховая плюс накопительная пенсии, работодатель отчислял 6\% на формирование накопительной пенсии (в ПФР или НПФ) и оставшиеся $16 \%$ - на страховую пенсию.

Накопительная пенсия являлась более индивидуализированной частью пенсии; в отличие от страховой пенсии, она не имела солидарный характер. Накопленные средства (6\%, которые работодатель с каждой зарплаты работника отчислял в ПФР или НПФ) не индексировались, но инвестировались выбранным страховщиком, чем и обеспечивалась их сохранность. Это - длинные деньги, важные для развития экономики страны. К тому же накопительной частью можно распоряжаться в различных обозначенных законом обстоятельствах и даже унаследовать.

С 2014 г. отчисления на формирование накопительной части пенсии для россиян заморожены. Мораторий продлен до 2020 г. Заморозка накопительной части говорит о несостоятельности предложенной системы и используется как инструмент сокращения дефицита бюджета ПФР. При введении системы ИПК 
предполагается 2-летний переходный период. В течение данного периода граждане, у которых сформирована накопительная часть пенсии, могут или перевести накопления в дополнительные баллы, или отправить как первый взнос в систему ИПК. Средства так называемых молчунов в течение этого срока будут автоматически переведены в дополнительные баллы, что является завершением их участия в накопительной системе.

На сегодняшний, 2019 г. отчисления в Пенсионный фонд России делает работодатель от фонда оплаты труда, не удерживая их из заработной платы, как при выплате НДФЛ. Работодатель отчисляет $30 \%$ от уровня зарплаты каждого сотрудника: $22 \%$ - в ПФР, 5,1\% - в ФОМС (федеральный Фонд обязательного медицинского страхования) и 2,9\% - в ФСС (Фонд социального страхования РФ). Это значит, что все $22 \%$ отчислений, которые делает работодатель, идут на формирование страховой пенсии. То есть, эти денежные средства используются для выплаты пенсии существующим пенсионерам и параллельно формируют право граждан на выплату им в будущем пенсии. Это право имеет численное выражение в виде индивидуального пенсионного коэффициента, который, в свою очередь, зависит от дохода гражданина. Его будущая пенсия будет формироваться из базовой государственной выплаты (фиксированная сумма) и выплаты по этому коэффициенту, стоимость которого дважды в год определяется Правительством РФ.

Отметим, что на величину индивидуального пенсионного коэффициента также влияют так называемые нетрудовые периоды: это уход за детьми, инвалидами; прохождение службы в армии; сопровождение супруга в дипломатических и военных поездках. Заметна позитивная тенденция изменения пенсионной системы в сторону дифференциации в соответствии с потребностями населения.

Экономическая обстановка последних лет привела к снижению темпов роста доходов населения, что напрямую отражается на сберегательном поведении населения. И хотя есть способы заниматься пенсионными накоплениями самостоятельно, в рамках ДПС (добровольное пенсионное страхование) или иными способами, низкие доходы граждан и, возможно, недоверие к финансовым институтам приводят к непопулярности таких услуг.

Измененную концепцию формирования накопительной части пенсии предложил Минфин России совместно с Центробанком в законопроекте об индивидуальном пенсионном капитале (далее - ИПК) еще в 2016 г.

В 2017 г. предполагалось, что годом начала введения системы ИПК станет 2019 г. Однако свод изменений ${ }^{1}$, начавший свое действие с января 2019 г., отсрочил реализацию проекта ИПК. Общественное обсуждение законопроекта предполагалось еще в августе 2018 г., однако до сих пор текст документа не опубликован ${ }^{2}$.

Сейчас планируемое время введения системы ИПК - 2020 г. Основной обсуждаемый вопрос заключается в выборе, как именно переводить граждан на систему ИПК - автоматически или в заявительном порядке.

При внедрении ИПК предполагается переход на полностью солидарный тариф, т.е. все $22 \%$ заработной платы, которые перечисляет работодатель из фонда заработной платы, будут идти на распределительную систему - на пен-

\footnotetext{
1 Федеральный закон № 350-Ф3 от 03.10.2018 «О внесении изменений в отдельные законодательные акты Российской Федерации по вопросам назначения и выплаты пенсий». Доступ: http://www. consultant.ru/document/cons_doc_LAW_308156/(проверено 16.03.2019).

2 Силуанов объяснил перенос обсуждения реформы накопительной пенсии. - Информационное агентство «РБК». 25.12.2018. Доступ: https://www.rbc.ru/economics/25/12/2018/5c2139aa9a7947ebb6f1f 3b1 (проверено 28.02.2019).
} 
сии тем, кто уже достиг пенсионного возраста. По сути, это возврат к распределительной системе, и многие эксперты оценивают этот шаг как возврат к финансовой системе пенсионного обеспечения, существовавшей 15 лет назад.

Накопительный элемент ИПК позволяет гражданам взять на себя ответственность и самостоятельно предпринять усилия по формированию дополнительных доходов, которые они смогут получить по окончании трудовой деятельности. Однако предполагается подключение всех работников трудоспособного возраста автоматически или в заявительном порядке к программе ИПК и осуществление платежей в форме добровольных отчислений именно от заработной платы работника со ставкой от $0 \%$ в первый год, $1 \%$ - во второй и так через ежегодное повышение - до 6\%. Отметим, что для граждан возможна заморозка \% ставки сроком на 5 лет.

Подключение граждан изначально предполагалось осуществлять автоматически, основываясь на ст. 158 Гражданского кодекса РФ «Форма сделок», п. 3 которой гласит, что «молчание признается выражением воли совершить сделку в случаях, предусмотренных законом или соглашением сторон».

Предлагается автоматическое подключение граждан, имеющих высокий уровень заработной платы, предположительно от 85 тыс. руб. в месяц. Однако данная категория граждан может подать заявление и выйти из системы. Сроки выхода обсуждаются. Граждане с уровнем заработной платы менее указанной суммы подключаются к системе ИПК после подачи заявления.

Схема с автоматическим подключением классифицируется как квазиобязательная частная система негосударственного пенсионного обеспечения. В таком случае категория граждан, проявляющих пенсионную инертность, например такая категория, как «молчуны» (граждане, средства пенсионных накоплений которых не переведены в НПФ, а так и остались в ПФР), будет задействована в пенсионной активности, и им придется хотя бы поверхностно разобраться в том, что они пишут в заявлении. Одной из проблем, существенно мешающих развитию НПО, является низкая финансовая грамотность населения в вопросах пенсионного обеспечения. Например, по результатам авторского исследования можно сделать вывод, что такое понятие, как «заморозка пенсий», многие соотносят исключительно с заморозкой пенсионных выплат существующим пенсионерам и не понимают механизма накопительной пенсии.

Сам проект ИПК направлен на стимулирование негосударственного пенсионного обеспечения (НПО) и на достижение социально приемлемого уровня пенсионного обеспечения. Предполагается, что добровольные взносы с зарплаты смогут и захотят осуществлять представители среднего класса - именно они смогут обеспечить себе достойную пенсию.

От ИПК можно будет отказаться в форме «каникул», которые фиксируют процентную ставку отчислений и которые можно продлевать каждые 5 лет на протяжении всей жизни. За свои отчисления граждане получают налоговую льготу - вычет по НДФЛ до 6\% заработка. В спорности проекта ИПК сомнений нет. Россияне действительно не расположены к длительным сберегательным стратегиям, тогда как пенсионные накопления являются самыми долгосрочными сбережениями; к тому же, будучи наученными горьким опытом заморозки накопительных частей пенсии, продленных до 2019 г., не многие будут готовы охотно отчислять процент от зарплаты в пользу ИПК. Этот вопрос решен в проекте таким образом, что ИПК становится частной собственностью граждан. Предполагается, что уже накопленные обязательства в виде объема накопительных пенсий в рамках ОПС станут частью ИПК. Однако точно об этом узнать можно, лишь увидев сам документ. 
При внедрении концепции ИПК в действие перед гражданами встанет ряд вопросов: например, какому НПФ они доверяют настолько, что готовы хранить в нем свои личные пенсионные накопления в течение долгих лет до выхода на пенсию. Важно понимать, что при реализации проекта ИПК граждане столкнутся с необходимостью выбора НПФ или УК, в который они будут отчислять уже собственные средства, а не средства работодателя. То есть, доверие к таким НПФ и лояльность клиентов должны оправдаться в долгосрочной перспективе ожидания.

По данным Аналитического центра НАФИ 1 , доверие россиян к банкам растет и сейчас находится на отметке в 65\% (16\% полностью доверяют и $49 \%$ скорее доверяют). Согласно тому же исследованию, доверие к НПФ находится на уровне $15 \%^{2}$.

Привлекая клиентов, НПФ сообщают о более высокой доходности своих инвестиций, однако из данных ежегодного обзора АНПФ за 2017 г. и начало 2018 г. следует, что только один из всех существующих НПФ по доходности средств накопительной пенсии смог обогнать ВЭБ. К тому же до сих пор не введена фидуциарная ответственность (материальная ответственность руководства фонда перед клиентами) НПФ. Далеко не все фонды раскрывают детали отчетности, связанные с тем, в какие бумаги они инвестируют имеющиеся средства.

Государство стало ужесточать требования к НПФ. Так, в 2015 г. для НПФ стали обязательными прохождение процедур акционирования и вступление в систему гарантирования пенсионных накоплений (АСВ). Второй сложностью в существовании НПФ стал мораторий 2014 г. - запрет на перевод средств пенсионных накоплений. Таким образом, число НПФ снизилось со 120 в 2014 г. до 92 в 2018 г.

Субъективные показатели пенсионных стратегий - это данные опросов, проведенных исследовательскими социологическими центрами. Пенсионные стратегии могут определяться ответами респондентов на вопросы анкет: это мотивационные, определяющие причины того или иного действия или мнения; ситуационные, показывающие возможное поведение или реакцию человека на ситуативное событие.

В 2018 г. авторы провели социологическое исследование, целью которого являлись изучение и систематизация существующих пенсионных стратегий населения. Исследование проводилось методом глубинного интервью, объект исследования - граждане РФ, жители мегаполиса предпенсионного возраста, вошедшие в систему формирования пенсионных накоплений в 2002 г. (старше 40 и моложе 50 лет).

Под пенсионной стратегией в исследовании понималась совокупность силы двух факторов: самостоятельности действий в рамках пенсионной системы и уровня доверия государству как гаранту пенсий.

Исследование показало, что доверие пенсионной системе и государству как страхователю (в роли ПФР), а также НПФ у людей низкое. Помимо этого, важной проблемой оказалась невысокая пенсионная грамотность и низкий уровень информированности о пенсионных нововведениях. В результате исследования были выявлены 4 вида пенсионных стратегий: пенсионный нигилизм, пенсионный патернализм, пенсионное партнерство и самостоятельная пенсионная активность.

\footnotetext{
1 Репрезентативный всероссийский опрос НАФИ проведен в ноябре 2018 г. Опрошены 1600 чел. в 140 населенных пунктах 42 регионов России. Возраст: 18 лет и старше. Статистическая погрешность не превышает $3,4 \%$.

2 Доверие россиян к банкам растет. - Аналитический центр НАФИ. 17.01.2019. Доступ: https://nafi. ru/analytics/doverie-rossiyan-k-bankam-rastet/ (проверено 01.03.2019).
} 
Анализ особенностей выделенных пенсионных стратегий позволяет сделать следующие выводы.

Во-первых, приверженцы стратегии пенсионного партнерства положительно оценят введение ИПК и в меру материальных возможностей попробуют принять в нем участие.

Во-вторых, приверженцы стратегии пенсионного патернализма в силу высокого доверия государству как гаранту пенсии, с одной стороны, и низкого уровня собственной активности - с другой, также положительно оценят введение ИПК. Однако если им придется самостоятельно подключаться к данной системе и выбирать из негосударственных пенсионных фондов подходящий, то они могут и не принять участие в системе ИПК, просто не написав заявление или из-за недоверия НПФ.

Группа граждан, близких к стратегии самостоятельной пенсионной активности, могут не поддержать внедрение системы ИПК, с одной стороны, из-за недоверия государству как гаранту достойной пенсии, а с другой - в силу собственной активности. Отметим, что это часто группа с высокими доходами, которая либо уже принимает участие в НПО, либо имеет иной надежный планируемый источник доходов на пенсии: инвестиции, недвижимость, вклады и др.

Что касается стратегии пенсионных нигилистов, которая предполагает как недоверие государству, так и низкий уровень социальной активности, то тех из них, кто не является протестно настроенным, проект ИПК сможет заставить задуматься о будущей пенсии. На наш взгляд, самое важное, что несет в себе проект ИПК, - это необходимость взять на себя ответственность и задуматься об источнике формирования доходов на пенсии.

Таким образом, при внедрении концепции ИПК необходимо провести массовую рекламную кампанию, включающую в себя инструктаж (в виде лекций) на местах работы с выдачей информационных брошюр с описанием возможностей квазиобязательной программы. Здесь же уместным будет объяснение принципов работы НПФ и составление списков рекомендуемых и не рекомендуемых НПФ для определения накопительной части в рамках ИПК. И главное, необходимо формировать доверие населения государству и его реформам.

RAZOV Pavel Vikłorovich, Dr.Sci. (Soc.), Associate Professor; Professor of the Department of Sociology, History and Philosophy, Financial University under the Government of the Russian Federation (49 Leningradsky Ave, Moscow, Russia, 125993; pvrazov@fa.ru)

YUSHKOVA Svetlana Aleksandrovna, Cand.Sci. (Econ.), Dr. Habilitatus, Associate Professor; Associate Professor at the Department of Sociology, History and Philosophy, Financial University under the Government of the Russian Federation (49 Leningradsky Ave, Moscow, Russia, 125993; ysa67@mail.ru).

DOROSHENKO Marina Vital'evna, Marketing Communications Specialist, Branding Agency Style You (off. 112, bld.23, 36 Kutuzovsky Ave, Moscow, Russia,121170; mar.dorosh95@gmail.com)

\section{INDIVIDUAL PENSION CAPITAL: ACTION STRATEGIES}

Abstract. The article discusses aspects of individual pension capital (IPC) instead of the existing funded pension system of Russia. The authors correlate positive and negative sides of this stage of pension reform; make forecasts and recommendations; and make assumptions about the specifics of reactions to the IPC system by citizens with different pension strategies.

Keywords: individual pension capital, pension reform, pension system, pension strategies 